\title{
The Impact of a Continuous Replenishment Program on Organisational Flexibility
}

\author{
Evangelia Kopanaki, Steve Smithson \\ London School of Economics, Houghton Street, London WC2A $2 A E$
}

\begin{abstract}
It is often argued that inter-organisational systems (IOS) can increase organisational flexibility. A Continuous Replenishment Program (CRP) is an EDI-based IOS that aims to match product flow with consumer demand, yielding improvements in inventory management and logistics. Our aim is to understand not only how the use of CRP affects the complex notion of flexibility, but also how organisational and inter-organisational issues influence the impact of this technology. Flexibility is, thus, examined not only as a characteristic of an individual firm, but also as a property of the interaction between firms. Flexibility is also perceived as a dynamic characteristic changing over time, influenced by the organisational and interorganisational context. A case study of a grocery retail supply chain forms the basis of our research.
\end{abstract}

Keywords: Interorganisational Systems, CRP, EDI, Organisational Flexibility.

\section{INTRODUCTION}

The ability of an organisation to be flexible is seen as beneficial, since it results in competitive advantage, and forms part of the survival kit of organisations (Avison, Powell et al. 1995). Interorganisational systems, such as EDI, have been proposed as an avenue towards organisational flexibility since they increase responsiveness to customers, decrease co-ordination costs and facilitate the creation of partnerships (O' Callaghan 1998). However, the use of EDI also imposes certain constraints and does not provide equal benefits to all trading partners (Swatman and Swatman 1992; Iakovou, Benbasat et al. 1995).

A specific type of EDI system that seems to offer many benefits is CRP (Continuous Replenishment Program) (Pramataris, Doukidis et al. 1997). It

\footnotetext{
The original version of this chapter was revised: The copyright line was incorrect. This has been corrected. The Erratum to this chapter is available at DOI: 10.1007/978-0-387-35617-4_48 
aims to match the flow of products to the consumer's actual demand, yielding improvements in manufacturing and warehousing activities. It is an EDI-based ordering system that also contains a DSS (Decision Support System), enabling product flow prediction and inventory management. However, the system's implementation and use also impose constraints.

Previous studies have examined flexibility solely as a characteristic of an individual firm (Golden and Powell 1997; O' Callaghan 1998) and their focus was mainly to investigate how organisational issues, such as the firm's size and technological awareness, influenced the impact of technology.

In this paper, we show that these issues are not sufficient to examine the impact of IOS on an organisation's flexibility. As IOS spread beyond the boundaries of a single organisation, additional factors, such as the relationships with trading partners also need to be considered. Therefore, the concept of flexibility needs to be viewed not only as a characteristic of a single firm, but also as a property of the relationship between firms. We have thus adopted two levels of analysis: the organisational level and the interorganisational (business network) level, which refers to the dyad, i.e., the interaction between two trading partners.

This paper proposes an interpretive approach to explain the multifaceted concept of flexibility. A research framework, based on systems thinking ideas and on previous research, enabled us to examine the concept of flexibility both at the organisational and interorganisational level. In the proposed framework, flexibility is presented not only as the ability of the organisation/business network to respond to environmental disturbances, but also as its capability to evolve and change over time. The process of change is viewed at an operational, structural or strategic level and the ability to change is indicated by issues of efficiency, adaptability and versatility. An exploratory case study in a grocery retail supply chain in Greece provides us with the necessary empirical data. We examine the experience of a leading multinational supplier, illustrating how the interaction with trading partners influenced the impact of technology on flexibility.

In the next section, we describe the emergence of the Efficient Consumer Response (ECR) initiative and the development of CRP, as a system supporting ECR's core objectives. In the third section we review the literature of flexibility, which led to the creation of the proposed research framework. Our research approach is described in the fourth section, followed by the research findings, discussion and conclusions. 


\section{CONTINUOUS REPLENISHMENT PROGRAM}

Efficient Consumer Response (ECR) emerged from the 1992 conference of the US Food Marketing Institute as a 'strategic initiative', involving management methods, practices and technologies, to enable distributors and suppliers to collaborate to deliver better value to consumers (Pramataris, Doukidis et al. 1997). In 1995, leading European manufacturers and retailers have created the ECR Europe Committee, which has been followed by the establishment of similar national committees, e.g. ECR Hellas in Greece. Their aim was to promote the ECR concept, launch and coordinate projects.

CRP emerged as an EDI-based system supporting the objectives of Efficient Replenishment, which are to maximise product availability with a minimum of inventory and handling through the supply chain. It extends the use of EDI links to accommodate the exchange of inventory information. It handles ordering by shifting responsibility from the retailer to the supplier. In the most common form of CRP the retailer's central warehouse sends an inventory report to the supplier, including information such as stock availability, store orders and products in-transit. By processing this information based on product flow predictions, the system at the supplier's side issues a suggested order and sends it back to the retailer. The aim is to ensure that the retailer's warehouse can meet the predicted demand, while keeping inventory levels as low as possible.

The benefits provided by the system, both to retailers and suppliers, comprise a reduction in the cost and time taken for ordering, improved inventory management, cost savings due to stock optimisation, better management and scheduling of deliveries and improved customer service. Ideally, the flow of products is matched to the consumer's actual demand yielding improvements in manufacturing, warehousing and transportation.

However, CRP also imposes constraints, especially for smaller organisations. We can, therefore, argue that the extent to which CRP affects organisational flexibility warrants investigation.

\section{ORGANISATIONAL FLEXIBILITY}

Anchored in different disciplines, the complex notion of flexibility mirrors a plethora of explanations and definitions. In general, "flexibility" is the ability of an organization to adapt when confronted with new circumstances, defend quickly against threats, and move rapidly to take advantage of opportunities (Lucas and Olson 1994; Golden and Powell 2000 ). It is the ability of an organisation to respond to an environmental threat and to predict a future threat and take actions in order to cope with it. 
The notion of flexibility, as a property of interaction between the organisation and its environment is explained in systems thinking, whose core comprises the concept of a whole entity (organism), which can adapt and survive, within limits, in a changing environment (Checkland 1999).

These ideas can be traced back to Cybernetics I (Emery 1969), where organisations are seen as a special class of open system, which are in constant interaction with their environment, transforming inputs into outputs as a means of creating the conditions necessary for survival. A richer perspective is provided by 'soft' systems thinking, from which Checkland and Casar (1986) developed the appreciative systems model. "The starting point for the model ... is the interacting flux of events and ideas unfolding through time." The events and ideas generate appreciation, which "is occasioned by our ability to select, to choose. Appreciation perceives (some of) reality, makes judgements about it, contributes to the ideas stream, and leads to actions that become part of the events stream" (Checkland 1995; p.6-7). The basic form of the model is shown in "Figure 1". "There is a recursive loop in which the flux of events and ideas generates appreciation, and appreciation itself contributes to the flux". The appreciative system is always open to new inputs from the flux of events and ideas and through its actions it reproduces a continually changed self (Checkland 1995). However, viewing the organisation as a system that continually reproduces itself or produces a changed self needs an approach that perceives flexibility as a dynamic characteristic evolving over time.

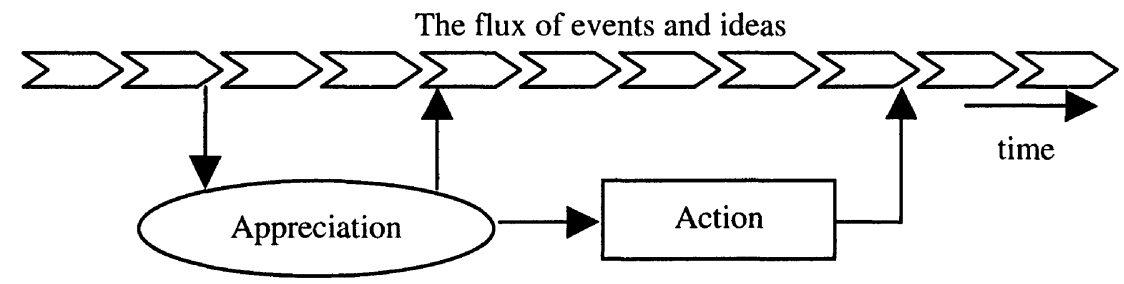

Figure 1: The structure of an appreciative system. Source Checkland and Casar 1986

The notion of flexibility in systems thinking is thus not only the ability of organisations to respond to environmental disturbances, but also their capability to evolve and change over time. De Leeuw and Volberda (1996) term this capacity to respond as adaptability. Evans (1991; p.73) argues that adaptability is the most common term whose meaning overlaps with flexibility. In systems thinking, adaptability does not only mean a singular and permanent adjustment to a newly transformed environment, but also implies the ability to make successive and temporary accommodations through interaction with the environment. According to Golden and Powell (2000) the extent to which an organisation has planned for, and can respond to, environmental changes can be measured by versatility, which is the 
variety of options available to respond to situations (Evans 1991). Besides versatility, Golden and Powell (1997) propose efficiency and responsiveness as additional measurements of flexibility, where efficiency is the ability to accommodate change with minimal performance degradation and within certain time constraints and responsiveness is the capacity to respond to change within an appropriate time limit. However, the distinction between efficiency and responsiveness is not straightforward, since a faster response could signify either responsiveness or efficiency. Hence, many researchers have treated responsiveness as part of efficiency.

We argue that the combination of adaptability, efficiency and versatility provides a better understanding of the notion of flexibility and we use these as indicators of the level of flexibility achieved. However, this approach does not enable us to identify the different types/levels of organisational flexibility. We, thus, also incorporate the classification of operational, structural and strategic flexibility (Volberda 1996). Since our perspective views flexibility also as a property of the relationship between trading partners, we have redefined these types of flexibility in order to apply them both at the organisational and interorganisational levels.

'Operational flexibility' is now defined as the ability of the organisation/business network to change the volume, mix and kind of activities based on its current structures. 'Structural flexibility' is the capability to adapt or transform the current structure or workflow of activities. At the interorganisational level, the structure of a network refers to the overall pattern of relationships. Transforming current structure could thus mean, creating new partnerships or dismantling old ones. 'Strategic flexibility' seems to be the most radical type of flexibility and could involve fundamental renovation of activities, products, and organisational structures. It also revolves around the ability to identify market trends before competitors and to make appropriate changes to synchronise production with demand.

The ability to change at the operational, structural and strategic level is indicated here through the concepts of efficiency, adaptability and versatility. These levels of flexibility are also influenced by the organisational and inter-organisational context, which can be defined by taking into account the relations of participants and the available infrastructure (Kling 1987).

Systems thinking ideas enabled us to understand flexibility not only as a property of the interaction with the environment, but also as a characteristic of the self-changing process of the organisation/business network. Following Volberda's work, we distinguished between the operational, structural and strategic levels of flexibility and we used efficiency, adaptability and versatility as indicators of the flexibility achieved at each level. The 
combination of these ideas led us to the creation of the following research framework.

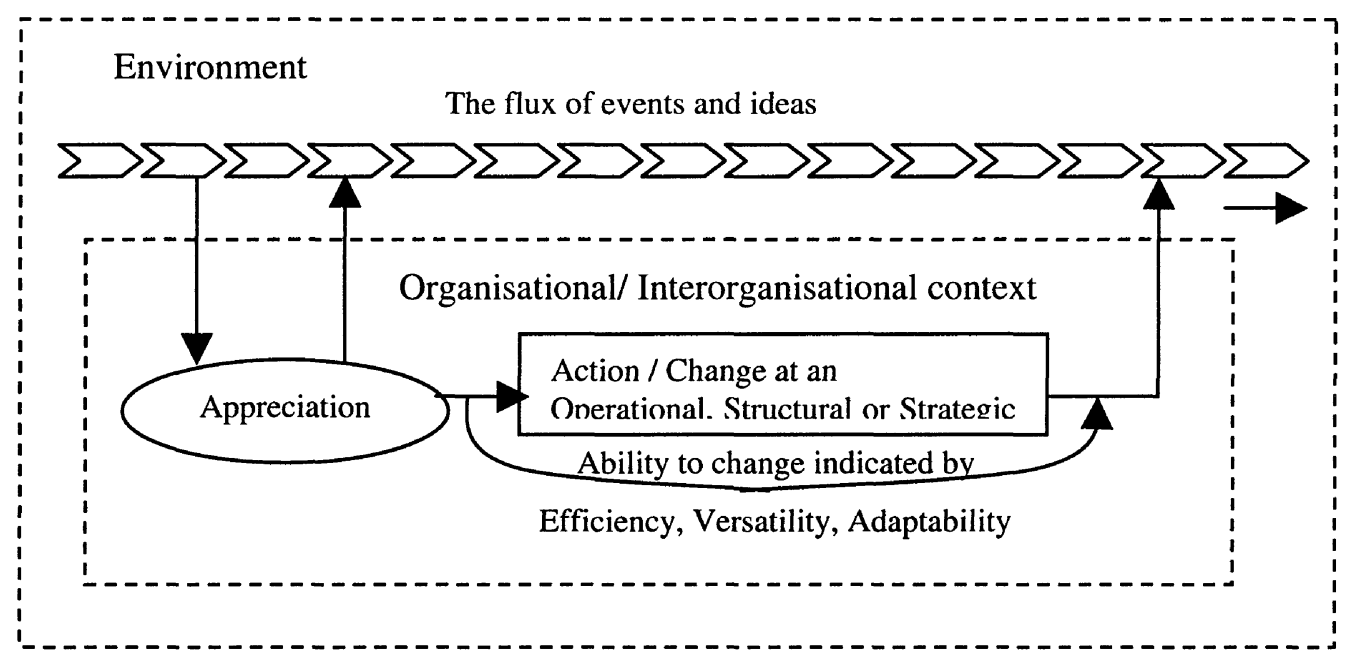

The organisation/business network responds to a continuous flux of events and ideas that derive either from the environment or from the organisation/business network itself. Flexibility is seen not only as the ability to react to anticipated or unanticipated environmental disturbances, but also as the capability to reproduce a continually changed self. The organisation/business network reacts to the incoming events through the process of appreciation. Appreciation can be conducted either by a person or by a system with embedded business logic. For example, demand changes are handled by the CRP system, which automatically adjusts the safety stock levels. The outcome of appreciation is an action or change at an operational, structural or strategic level. The ability to change at each level is indicated by the concepts of efficiency, adaptability and versatility. The process of appreciation and subsequent action/change are influenced by the organisational/interorganisational context. There is a recursive loop in which the flux of events and ideas generates appreciation, while appreciation itself leads to action/change. This change can impact the environment, especially if it is a strategic change, or can affect the organisation itself, by provoking another event or idea.

\section{RESEARCH APPROACH}

Although the focus of our study was to examine how the use of IOS affects flexibility, we needed to extend our scope to take into account not only technological, but also organisational and inter-organisational issues. This multi-disciplinary nature of IOS suggests the adoption of a holistic approach. 
Although positivist research is still the dominant approach in information systems (Orlikowski and Baroudi 1991), it cannot provide the richness of a holistic perspective. Positivist researchers seek to provide generalisable evidence about organisations through systemic prediction and observation, but they often neglect the social context and fail to capture the complexity of reality. On the contrary, interpretivism (Walsham 1995) is concerned with approaches to the understanding of reality. Interpretivist researchers seek relevance of the research by explicitly including an investigation of the context of the phenomenon under study. We can, therefore, argue that an interpretive perspective is more suitable for our study.

To acquire a more holistic view of flexibility, we followed a case study approach. One of the main weaknesses of interpretivist case research is the inability to generalise findings statistically to a population (Cavaye 1996). In this study generalisability is allowed through the selection of a multiple case design. This enables the analysis of data across cases and allows researchers to relate differences in context to constants in process and outcome. It also allows them to verify that findings are not merely the result of idiosyncrasies of the research setting (Cavaye 1996).

By following a multiple case approach we were able to understand how different organisational contexts influenced the impact of technology on organisational flexibility. Our empirical work was conducted over a period of 10 months in a grocery retail supply chain in Greece. In order to examine different organisational contexts, we selected our sites (3 suppliers and 4 retailers) based on the characteristics of firms, such as size, structure and technological infrastructure. Among the multinational suppliers, we chose two large organisations that use CRP with various retailers and, therefore, have a better view of the benefits. We also selected a smaller supplier who lacks the resources needed to implement CRP. From the retailers we chose two large multinationals that use CRP with the two large suppliers mentioned above, a large Greek company that has not yet implemented CRP and a smaller retailer that was unsuccessful in using CRP. For data collection, we used semi-structured interviews, documentation and limited participant observation.

Due to space limitations, we do not present findings involving all organisations. Our objective is to illustrate the constraints that CRP can impose even to the more competent organisations. We have, thus, selected a sub-network involving one large multinational supplier, two large multinational retailers and the smaller local retailer. 


\section{RESEARCH FINDINGS}

Most large retailers and suppliers in Greece work together under the umbrella of ECR Hellas to standardise management practices and technology implementation to facilitate their operations and co-operation. The majority of firms were not able to implement CRP due to an inability to do the required business process reengineering, a shortage of skills, problems of incompatibility, the high cost of implementation and maintenance and a lack of technological awareness. The organisations that implemented CRP were mainly large multinational companies and they have gained efficiency, cost savings and improved co-operation with their trading partners. However, whether they have also gained flexibility is less clear.

The analysis of our empirical data, based on the application of the framework to the above sub-network, treats flexibility as the ability to respond to the flux of events or ideas, arising either from within the organisation/business network or from the external environment (including unexpected events, e.g. a very hot summer). Emphasis is given on the ability of the organisation/dyad to act/change at an operational, structural or strategic level and not on the process of appreciation that leads to the action. The ability to change at each level is indicated by efficiency, adaptability and versatility. Our aim is not only to demonstrate the impact of CRP on the flexibility of the supplier, but also to describe how the relationships with its trading partners affect the usage of the system.

\subsection{Operational flexibility}

\subsubsection{Organisational level}

The operational flexibility of the supplier has been increased to a certain extent. CRP enabled the supplier to respond more efficiently to everyday situations. The automated posting of orders, the elimination of errors and the reduction of ordering time facilitated the issuing and processing of orders and increased the supplier's responsiveness.

By using CRP we became more responsive to our retailers' needs. Orders are handled very quickly and the number of mistakes is diminished. Prior to the system's installation a mistake could result in the customer being left out of stock [IT manager].

The automated posting of orders also affected the work of sales managers, since they do no longer need to go to the retailers' central warehouses, to take the orders. They have thus more free time to deal with more important issues such as sales initiatives. 
Without CRP, we needed approximately 2.5 hours to prepare an order. We do not need to spend time in negotiations anymore. We are now able to stay more inside our customer's stores, arrange promotions and product shelving. Our job became more interesting [Sales manager].

The use of CRP also improved the supplier's production management, logistics and inventory management, resulting in better planning of deliveries, cost savings and better utilisation of warehouse space.

The money saved can be used for other activities, such as promotions [Head of Sales department].

Through better stock management and utilisation of storage we can deal with unusual situations, like returned products from retailers or an unexpected delivery from our manufacturers [Warehouse manager - supplier].

These improvements enable them to deal better with crisis situations. They can thus respond more efficiently to unusual events, without being constrained by lack of information, storage and products. Therefore, their availability of options to respond, that is their versatility, is increased.

However, the use of this technology limits the adaptability of certain operations. For example, once a proposed order is submitted, the system does not allow any changes. If, for instance, they forget a promotion, they have to wait for the next day to include it.

Nevertheless, as described below, the operational flexibility at the organisational level can be significantly affected by the flexibility of trading partners.

\subsubsection{Inter-organisational level}

The benefits gained from CRP are not the same for each dyad but are influenced by the flexibility and mode of operation of trading partners. If a trading partner is not flexible then their co-operation is also inflexible, as can be seen from the very different results achieved with two retailers described below.

Retailer A, a multinational that implemented CRP in 1996, has fully integrated CRP with its internal information system, through software bridges built in-house. Since then the supplier and retailer A used the system without problems. The improvements in ordering increased the efficiency of their interaction and provided flexibility to both trading partners. It also improved their relationships and co-operation.

The process of ordering was speeded up and we, thus, became more responsive. This customer's inventory report is always accurate and we do not spend time to correct mistakes [CRP Analyst] .

The elimination of mistakes as well as the successful results of CRP, made our customer to trust us more. Our co-operation improved and we can thus handle more easily changes of products. For example, in case of a product replacement we gradually diminish the stock availability of the old one, in order to be able to send the new one, when needed [CRP Analyst]. 
Besides the exchange of CRP orders, retailer A also supports the exchange of PRICAT (price catalogue) messages. These EDI messages contain the characteristics of a product, such as code, weight, volume, units per case and cases per pallet. This means that the retailer's warehouse system is automatically informed of new products, increasing not only the efficiency, but also the adaptability of certain operations.

It is easy to change products and distribute them to supermarkets. The issuing of a new product is done efficiently, and an order including this product can be created immediately. We can thus focus on more important issues such as product shelving and promotions [Sales Manager].

On the contrary, some retailers are not flexible and this affects the flexibility of the interaction. Retailer B, is a large multinational company that has implemented CRP without supporting the exchange of PRICAT messages. The latter causes delays in the issuing and replacement of product codes and the distribution of products to the market. These delays are exacerbated by the retailer's technological infrastructure, which comprises of two incompatible systems in the central offices that do not communicate with the systems of all supermarkets. Furthermore, due to a cumbersome organisational structure, numerous people are responsible for the insertion of the new product codes, which leads to additional errors and inconsistencies in the two systems. Correcting these mistakes requires close co-operation between those responsible, but this is handicapped by the technological constraints and organisational structure. The adaptability and responsiveness of both supplier and retailer are thus further limited.

Without issuing a product code into their system they can neither accept the proposed CRP order nor receive the products, when delivered to their central warehouse. This leads to delays in the delivery of products to supermarkets and return of products to the supplier [Sales Manager].

In order to circumvent the cumbersome technology of the retailer, responsibility was shifted to the supplier's sales managers.

Our sales managers have to make sure that the new product codes are issued on time to the retailer's systems, both in the warehouse and stores. They have to spend time resolving problems [Head of Sales Department].

These technological constraints, plus the lack of integration of the CRP with the retailer's internal IS, tend to produce errors within the CRP. The inventory report sent to the supplier is sometimes inaccurate. Without information regarding products in-transit and the actual stock, the supplier's CRP system cannot generate a correct order.

The co-operation between the two companies is, however, gradually improving. This is greatly helped by the good collaboration between the supplier's CRP analyst and the retailer's CRP user.

The CRP user manages to efficiently solve most of the problems that arise. Our good co-operation enables us to circumvent some technological constraints [CRP Analyst supplier]. 
The retailer's technological constraints are also gradually diminishing, following improvements in their internal system. The operational flexibility of this dyad is, thus, progressively increasing.

The use of CRP, however, can also produce constraints, regardless of the trading partner's efficiency. The sending of messages, at a specified time, limits the adaptability of the operation and prevents sending corrective or supplementary orders. In order to deal with these situations and overcome the technological constraints, staff usually need to side-step the system and communicate via telephone.

\subsection{Structural Flexibility}

\subsubsection{Organisational level}

Structural flexibility refers to the ability to change the current structure or workflow of activities. With the implementation of CRP, the workflow and organisational structure of the supplier became more efficient, rather than adaptable. To accomplish the desired workflow and gain adaptability they sometimes need to side-step the CRP with less advanced technology.

We produce Excel files, copies of CRP messages, to inform the sales managers of product demand. We cannot do that with CRP, as once the order is created it is automatically sent to our central warehouse [CRP Analyst].

Another limitation imposed by CRP is that it requires specialised and well-trained people, especially at the supplier's side. This supplier created a special role (CRP analyst) within the sales department, with responsibility for the system. Besides technical skills these analysts also need knowledge of the market. They check the automatically produced order, identify mistakes in the customer's inventory report and decide whether the suggested order needs to be changed, e.g. to include a promotional activity. For sales promotions or seasonal products they work closely with sales managers to determine the optimum quantities for customers. These specialised skills and knowledge mean that they are difficult to replace.

\subsubsection{Inter-organisational level}

At the interorganisational level, structural flexibility refers to the ability to establish new partnerships, but the implementation of CRP tends to inhibit the adaptability and expansion of the business network. Even powerful and competent organisations argue that implementing CRP with a new trading partner is not easy. The system needs to be installed and integrated with the organisation's internal IS. Individual CRP users have to be trained and the system needs to be tested for two or three months before its actual operation 
starts. This period of testing is required to gather product flow data and to train the system to produce orders, in order to keep an optimum level of stock.

According to the supplier, the very first implementation of the system with a retailer was the most difficult, but this was a learning experience and subsequent implementations were easier. However, they still need to spend time to test and train the system, and this requires close co-operation with the trading partner. The amount of time needed for the implementation depends on the trading partner. According to the IT manager, fast implementation is only feasible with highly competent partners, like retailer $A$, which have the appropriate expertise and technological infrastructure to support CRP. With retailer B, however, the whole process took much longer and due to their cumbersome infrastructure they still face problems with the usage of CRP.

Some retailers tried to implement CRP but had to abandon the whole project. Retailer C, a smaller company but still a member of ECR, recognised the potential benefits and joined a CRP project. After investing time and money in the implementation and testing of the system, they abandoned the whole project.

We worked together for some time and tried to make the system work. But, the implementation failed. This was however predictable, since the retailer did not even have a warehouse management system [CRP Analyst].

Smaller companies are generally less able to implement CRP. A supplier's sales manager suggested that this was due to a lack of technological awareness and appropriate infrastructure, as well as the high cost of installation and maintenance.

We could therefore argue that the structural flexibility at the interorganisational level is decreased. The use of CRP does not facilitate the establishment of partnerships but leads to the creation of a business network, which is rather closed and restricted to few organisations.

\subsection{Strategic Flexibility}

\subsubsection{Organisational level}

In the context of the grocery retail supply chain in Greece, strategic flexibility normally revolves around the ability to identify market trends before competitors and the capability to quickly match production to changes in demand. To this end, CRP has helped this type of flexibility not only directly but also indirectly.

The direct link is through the increased availability of information for decision-making. CRP messages provide key information regarding 
variations in product demand. This gives the supplier the opportunity to refine their sales and strategy, thus contributing to increased versatility. The use of CRP also brings efficiency, since its main objective is to try to match the product flow to the consumer's actual demand.

The indirect link can be seen in the change in sales managers' jobs. As noted above, the automation of some low level activities has given them time to observe the supermarkets, negotiate shelf arrangements for products, examine the market and initiate new promotions.

\subsubsection{Inter-organisational level}

The use of CRP is unlikely to contribute to increased strategic flexibility where this involves fundamental renovation of inter-organisational structure and activities, since this will primarily require an increased structural flexibility. It can, however, positively influence strategic flexibility by facilitating the accommodation of new types of products within the existing network structure, or by improving the availability of information for decision-making and by supporting close co-operation between trading partners. The co-operation between trading partners has improved not only by the use of technology, but also by their participation in ECR-Hellas.

\section{DISCUSSION AND CONCLUSIONS}

The argument that information systems, and especially IOS, can make a major contribution to organizational flexibility has been increasingly supported (Golden and Powell 1997; O' Callaghan 1998). The objective of this study was to clarify the concept of flexibility, not only as a characteristic of an individual firm but also as a property of the relationship between firms. Based on systems thinking and previous research, we proposed a research framework that perceives flexibility as the ability to respond to events or ideas stemming from the environment or from the organization/business network itself. We distinguish between operational, structural and strategic flexibility, both at the organizational and inter-organizational level and propose efficiency, adaptability and versatility as indicators of flexibility achieved at each level. In this paper, we focused on a multinational supplier and showed that although the use of CRP offers many benefits it does not guarantee a desirable level of flexibility even to the most competent organisations.

Operational flexibility increased since improvements in inventory management and logistics enabled the supplier to cope better with crises. But this type of flexibility was also influenced by the flexibility of trading partners. In some cases, the necessary co-operation and implementation of 
CRP took place without problems, leading to an increase of operational flexibility at the inter-organisational level. But, in other cases the problems faced constrained the efficiency of the interaction.

Structural flexibility decreased, both at the organisational and interorganisational level. Technology leads to a more efficient, but more rigid organisational structure and workflow of activities. It also makes the establishment of partnerships more difficult. The implementation and use of CRP requires time for testing and training. This can be reduced only when trading partners have the appropriate technological awareness and infrastructure to support the system. Conversely, the use of CRP with less competent partners can lead to many problems or even fail completely.

Finally, strategic flexibility seems to be only positively influenced through the availability of information for decision-making and the cooperation of trading partners to set common goals and strategies. This is accomplished not only by the use of technology, but also through the participation in the ECR Committee.

An important issue raised by both our framework and findings was the evolution or change in flexibility itself, over time. The supplier's sales department gained flexibility by extending the CRP system to produce Excel files. Moreover, the problems faced with retailer B, diminished over time. Their co-operation improved and their operational flexibility increased.

Besides the notion of time we have also identified issues of infrastructure and co-operation as being the prevalent factors influencing flexibility. Many problems with CRP arose due to the cumbersome infrastructure of retailer B. The company used two incompatible IS and the CRP was not integrated with the warehouse's system. This led to errors and reduced the operational flexibility at an interorganisational level. Problems also occurred at the establishment of CRP with retailer C. The lack of a warehouse management system, made the issuing of the inventory report difficult. On the contrary, the advanced infrastructure of retailer A and the CRP's full integration with their internal IS, contributed to a flexible interaction with the supplier.

The co-operation attained both at the organisational and interorganisational level, also proved to have a considerable impact on the flexibility achieved. The cumbersome organisational structure of retailer B tended to discourage co-operation between staff and limited their ability to solve problems. On the contrary, the interaction difficulties faced between the supplier and retailer B were largely overcome through co-operation between their respective CRP experts.

By conducting an interpretive case study we were able to understand the evolution of flexibility over time. We also identified the contextual issues that influenced the level of flexibility achieved. We have mainly focused on the co-operation between the participants concerned with the system and on the infrastructure available for its support, and we have shown the impact on 
flexibility. These issues, along with additional contextual issues of political relationships, could be used to enrich our framework and provide a more holistic view of the phenomenon under study.

\section{REFERENCES}

Avison, D., P. Powell, et al. (1995). "Addressing the need for flexibility in Information Systems." Journal of Management Systems 7(2): 43-66.

Cavaye, A. L. M. (1996). "Case study research: a multifaceted research approach for IS." Info Systems Journal 6: 227 - 242.

Checkland, P. (1995). Systems Thinking and Management Thinking. Critical Issues in Systems Theory and Practice. K. Ellis, A. Gregory, B.R. Mears-Young and G. Ragsdell. New York, London, Plenum Press: 1-14.

Checkland, P. (1999). Systems Thinking. Rethinking management information systems : an interdisciplinary perspective. B. Galliers and W. Currie. Oxford, Oxford University Press.

Checkland, P. and A. Casar (1986). "Vickers' Concept of an Appreciative System: A Systemic Account." Journal of Applied Systems Analysis 13: 3-17.

De Leeuw, A. C. J. and H. W. Volberda (1996). "On the Concept of Flexibility: A Dual Control Perspective." Omega, Int. J. Mgmt. Sci. 24(2): 121-139.

Emery, F. E. (1969). Systems thinking : selected readings. Harmondsworth, Penguin.

Evans, S. (1991). "Strategic Flexibility For High Technology Manoeuvres." Journal of Management Studies 28(1).

Golden, W. and P. Powell (1997). Inter-organisational Information Systems and the Gains From Organisational Flexibility. Proceedings of 5th ECIS, Cork, Ireland.

Golden, W. and P. Powell (2000). "Towards a definition of Flexibility: in search of the Holy Grail?" Omega, Int. J. Mgmt. Sci. 28: 373-384.

Iakovou, C., I. Benbasat, et al. (1995). "Electronic Data Interchange and small organisations: adoption and impact of Technology." MIS Quarterly, 19(2).

Kling, R. (1987). Defining the Boundaries of Computing Across Complex Organisations. Critical Issues in Information Systems Research. Chichester, John Wiley \& Sons Ltd.

Lucas, H. and M. Olson (1994). "The Impact of Information Technology on Organisational Flexibility." Journal of Organisational Computing 4(2): 155-175.

O' Callaghan, R. (1998). EDI, Organisational Change and Flexible Strategies. Information Technology and Organisational Transformation. John Wiley \& Sons Ltd.

Orlikowski, W. J. and J. J. Baroudi (1991). "Studying information technology in organisations: research approaches and assumptions." Information Systems Research 2(1).

Pramataris, K. C., G. I. Doukidis, et al. (1997). Exploring Information Systems Potential in the ECR Context. Proceedings of 5th ECIS, Cork, Ireland.

Swatman, P. M. C. and P. A. Swatman (1992). "EDI System Integration: A Definition and Literature Survey." Journal of the Information Society 8(3).

Volberda, H. (1996). "Toward the Flexible Form: How to Remain Vital in Hypercompetitive Environments." Organisation Science 7(4): 350 - 374.

Walsham, G. (1995). "Interpretive case studies in IS research: nature and method." European Journal of Information Systems 4: 74-81. 